\title{
Social cognition in multiple sclerosis
}

\author{
A systematic review and meta-analysis
}

Jack Cotter, MSc

Joseph Firth, BSc (Hons)

Christian Enzinger, MD

Evangelos Kontopantelis,

$\mathrm{PhD}$

Alison R. Yung, MD

Rebecca Elliott, $\mathrm{PhD}$

Richard J. Drake,

MRCPsych, PhD

Correspondence to

J. Cotter:

jack.cotter@manchester.ac.uk
Supplemental data at Neurology.org

\section{ABSTRACT}

Objective: To quantify the magnitude of deficits in theory of mind (ToM) and facial emotion recognition among patients with multiple sclerosis (MS) relative to healthy controls.

Methods: An electronic database search of Ovid MEDLINE, PsycINFO, and Embase was conducted from inception to April 1, 2016. Eligible studies were original research articles published in peer-reviewed journals that examined ToM or facial emotion recognition among patients with a diagnosis of MS and a healthy control comparison group. Data were independently extracted by 2 authors. Effect sizes were calculated using Hedges $g$.

Results: Twenty-one eligible studies were identified assessing ToM (12 studies) and/or facial emotion recognition (13 studies) among 722 patients with MS and 635 controls. Deficits in both ToM ( $g=-0.71,95 \%$ confidence interval $[\mathrm{Cl}]-0.88$ to $-0.55, p<0.001$ ) and facial emotion recognition ( $\mathrm{g}=-0.64,95 \% \mathrm{Cl}-0.81$ to $-0.47, \mathrm{p}<0.001$ ) were identified among patients with MS relative to healthy controls. The largest deficits were observed for visual ToM tasks and for the recognition of negative facial emotional expressions. Older age predicted larger emotion recognition deficits. Other cognitive domains were inconsistently associated with social cognitive performance.

Conclusions: Social cognitive deficits are an overlooked but potentially important aspect of cognitive impairment in MS with potential prognostic significance for social functioning and quality of life. Further research is required to clarify the longitudinal course of social cognitive dysfunction, its association with MS disease characteristics and neurocognitive impairment, and the MSspecific neurologic damage underlying these deficits. Neurology ${ }^{\circledR} 2016 ; 87: 1727-1736$

\section{GLOSSARY}

$\mathbf{C I}=$ confidence interval; EDSS = Expanded Disability Status Scale; $\mathbf{M S}=$ multiple sclerosis; $\mathbf{T o M}=$ theory of mind

Cognitive dysfunction is present in up to $70 \%$ of patients with multiple sclerosis (MS) and has been reported at all stages and in all subtypes of the disease. ${ }^{1-3}$ Deficits are most commonly reported in attention, processing speed, memory, and executive function. ${ }^{4}$ However, comparatively little is known about the impact of MS on social cognition, the "mental operations that underlie social interactions." ${ }^{5}$ Following pioneering work in autism, ${ }^{6}$ social cognitive impairment has been reported in a range of psychiatric, developmental, and neurodegenerative disorders. $^{7-10}$ In this review, we focus on theory of mind (ToM) and facial emotion recognition, 2 core aspects of social cognition that have been the subject of recent research in MS. Deficits in these social cognitive domains are associated with reduced social and psychological quality of life in patients with MS, even after controlling for severity and duration of disease, age, and neurocognitive performance. ${ }^{11}$ ToM refers to the ability to infer the intentions, dispositions, and beliefs of others and is thought to comprise distinguishable but overlapping cognitive and affective components. ${ }^{9,12}$ Facial emotion recognition refers to an individual's ability to identify and discriminate between the emotional states of others based on their facial expressions. Collectively these drive interpersonal skills such as empathy, and may have important

From the Institute of Brain, Behaviour and Mental Health (J.C., J.F., A.R.Y., R.E., R.J.D.) and Farr Institute for Health Informatics Research (E.K.), University of Manchester, UK; and Research Unit for Neuronal Repair and Plasticity (C.E.), Department of Neurology, Medical University of Graz, Austria.

Go to Neurology.org for full disclosures. Funding information and disclosures deemed relevant by the authors, if any, are provided at the end of the article. 
implications for social functioning. ${ }^{13}$ In this meta-analysis, we aimed to quantify the magnitude of deficits in ToM and facial emotion recognition among patients with MS relative to healthy controls. We also sought to explore the relationship between clinical, cognitive, and demographic factors and social cognitive performance.

METHODS This review was conducted in line with the Preferred Reporting Items for Systematic Reviews and MetaAnalyses guidelines. ${ }^{14}$

Study inclusion criteria. Eligible studies were original research articles published in peer-reviewed journals that examined ToM or facial emotion recognition among patients with a diagnosis of MS, as defined by the Poser or McDonald criteria. ${ }^{15,16}$ In order to be included, studies needed to include a healthy control comparison group and sufficient data to calculate an effect size. Where studies reported data from a subsample of patients from a larger study, only the larger study was included. No restrictions were placed on the age of patients or phenotype of MS for inclusion. Case studies, review articles, and non-Englishlanguage articles were excluded.

Search strategy. On April 1, 2016, we conducted an electronic database search of Ovid MEDLINE, PsycINFO, and Embase (from inception) using the following keyword search terms: "multiple sclerosis" and "social cognition" or "theory of mind" or "emotion." In addition, a basic search of Google Scholar was conducted and the reference lists of retrieved articles were also reviewed to identify any additional relevant publications.

Study selection and data extraction. Two of the authors (J.C. and J.F.) independently screened articles for eligibility. There were no disagreements regarding the inclusion of studies in this review. A standardized data extraction spreadsheet was used for all eligible studies to record the following: (1) study characteristics (year of publication, country where the work was performed); (2) social cognitive domains assessed and measures used; (3) MS and control sample demographics (sample size, sex, age, years of education, IQ); (4) MS disease characteristics (disease duration, disease course, medication, depression, fatigue, and degree of physical disability); (5) social cognitive performance for the MS and control groups (mean scores and associated SDs, or $t$ values). Where necessary, we contacted study authors for unreported data in order to calculate effect sizes. Facial emotion recognition tasks were defined as those that required participants to label or discriminate between images of faces depicting any combination of the 6 basic emotions (anger, disgust, fear, happiness, surprise, and sadness). ${ }^{17}$ ToM tasks required the identification of more complex mental states or the detection of factors such as lies, sarcasm, or faux pas using images, videos, or vignettes.

Statistical analysis. Data analyses were performed using Comprehensive Meta-Analysis version 3.0.18 Standardized mean differences (effect sizes) were calculated for both overall ToM and facial emotion recognition using Hedges g. This represents the difference between the means of the MS and healthy control comparison groups, divided by the pooled SD and weighted for sample size. For individual studies in which multiple measures were used to examine either ToM or facial emotion recognition, a pooled effect size and $95 \%$ confidence interval (CI) was calculated based on the mean of the effect sizes and corresponding standard errors for each task.

Additional supplementary analyses were also conducted to examine performance on the 3 most common types of ToM assessment: the Reading the Mind in the Eyes test, ${ }^{19}$ Faux Pas recognition tasks, and video-based ToM tasks. In addition to the overall facial emotion recognition analysis, individual effect sizes were also calculated for the patient's ability to correctly identify each of the 6 basic facial emotion expressions.

Due to clinical and demographic variation across study samples and in social cognitive assessments, a random-effects model was applied throughout. This provides more conservative estimates by accounting for observed heterogeneity, and is a better performing model compared to a fixed-effect approach..$^{20,21}$ Heterogeneity was quantified using the $P^{2}$ and $H^{2}$ statistics and their CIs. ${ }^{22}$ Publication bias was investigated using funnel plots, the Egger test, and the Rosenthal fail-safe number for effect sizes that were generated from at least 10 studies. The fail-safe number refers to the number of studies with an effect size of zero that would be required to make the $p$ value for the mean effect size nonsignificant (i.e., $p>0.05$ ).

Exploratory meta-regression analyses were conducted to examine evidence of variables moderating the effect of MS on $\mathrm{ToM}$ and facial emotion recognition. The following clinical and demographic variables from the MS group were identified a priori and examined in univariate analyses: age, sex (proportion of each sample that were male), years of education, disease duration, proportion with a progressive course of illness (primary, secondary, or progressive relapsing), and Expanded Disability Status Scale (EDSS) ${ }^{23}$ score (reflecting the degree of physical disability). These were selected for the exploratory analyses on the basis that they would be routinely available to clinicians. All metaregression analyses were performed using a random effects model.

RESULTS Study characteristics. The study selection process is summarized in figure 1 . We identified 21 eligible articles from 12 countries (table 1). Twelve studies examined ToM and 13 examined facial emotion recognition ( 4 examined both). One study reported outcome data separately for cognitively impaired and cognitively intact MS groups. ${ }^{24}$ As both groups had distinct clinical profiles, they were used and treated as separate data points in the meta-analyses. Another study included 8 patients with clinically definite MS and 12 with a clinically isolated syndrome suggestive of MS. ${ }^{25}$ This study was included in the relevant meta-analyses on the basis that a high proportion of patients with a clinically isolated syndrome go on to develop MS. ${ }^{26}$ However, additional sensitivity analyses were performed to examine the impact of this study on the results.

In total, 1,369 participants were included, 722 of whom had been diagnosed with MS, and 635 were healthy controls. The mean age of patients across samples was 39.9 years (range 16.3-52 years) and $67 \%$ were female. Control groups were generally well-matched to the MS groups with regards to age and sex and often for years of education and IQ, where reported. The mean disease duration was 8 


\begin{tabular}{|c|c|c|c|c|c|c|c|c|}
\hline Sample characteri & of included studies & & & & & & & \\
\hline Reference: Country & Social cognition tasks & Group & No. (F/M) & Age, $y$ & Education, y & Disease duration, $y$ & Disease course & EDSS \\
\hline \multirow[t]{2}{*}{ Banati et al. ${ }^{53}$ : Hungary } & ToM: RMitE, Faux Pas task, Adult Faces & MS & $40(29 / 11)$ & $36.2(9.4)$ & NR & 7.57 (6.29) & RR 37, SP 3 & NR \\
\hline & & $\mathrm{HC}$ & $35(18 / 17)$ & $33.4(7.8)$ & NR & - & - & - \\
\hline \multirow[t]{2}{*}{ Beatty et al. ${ }^{36}:$ USA } & FER: Ekman Faces & MS & 21 (NR) & 52 & 14 & 18.4 & $\mathrm{CP} 21$ & 6.6 \\
\hline & & $\mathrm{HC}$ & 19 (NR) & 51.1 & 14.4 & - & - & - \\
\hline \multirow[t]{2}{*}{ Berneiser et al. ${ }^{37}$ : Germany } & FER: FAB & MS & $61(44 / 17)$ & 42.2 & 14 & 6.1 & RR 47, PP 3, SP 11 & 3.65 \\
\hline & & $\mathrm{HC}$ & $53(33 / 20)$ & 38.5 & NR & - & - & - \\
\hline \multirow[t]{2}{*}{ Cecchetto et al..$^{38}$ : Italy } & FER: NimStim & MS & $30(21 / 9)$ & $34.2(6.2)$ & $14.7(2.0)$ & $9.1(6.7)$ & RR 30 & $2.0(1.0)$ \\
\hline & & $\mathrm{HC}$ & $30(21 / 9)$ & $32.5(6.4)$ & $15.2(3.1)$ & - & - & - \\
\hline \multirow[t]{2}{*}{ Charvet et al. ${ }^{27}:$ USA } & ToM: RMitE, Faux Pas task, False Belief task & MS & $28(19 / 9)$ & $16.29(3.12)$ & NR & $2.82(2.51)$ & RR 28 & 1 \\
\hline & & $\mathrm{HC}$ & $32(23 / 9)$ & $15.69(2.94)$ & NR & - & - & - \\
\hline \multirow[t]{2}{*}{ Genova et al..$^{30}$ : USA } & ToM: TASIT & MS & $15(11 / 4)$ & $49.5(8.0)$ & $15.0(1.8)$ & $17.98(10.3)$ & RR 10, PP 2, SP 2, PR 1 & NR \\
\hline & & $\mathrm{HC}$ & $15(5 / 10)$ & $38.9(13.1)$ & $14.7(2.3)$ & - & - & - \\
\hline \multirow[t]{2}{*}{ Henry et al. ${ }^{28}:$ Australia } & FER: Ekman Faces & MS & $27(18 / 9)$ & $47.0(11.01)$ & $15.0(3.44)$ & $7.0(6.08)$ & NR & NR \\
\hline & ToM: RMitE & $\mathrm{HC}$ & $30(19 / 11)$ & $44.3(9.55)$ & $14.8(2.57)$ & - & - & - \\
\hline \multirow[t]{2}{*}{ Henry et al. ${ }^{33}:$ France } & FER: FEEST & MS & $64(50 / 14)$ & $42.4(9.8)$ & $11.1(3.14)$ & $9.1(5.37)$ & RR 64 & $2.3(1.7)$ \\
\hline & ToM: Faux Pas task, False Belief tasks & $\mathrm{HC}$ & $30(21 / 9)$ & $38.6(13.9)$ & $12.4(3.25)$ & - & - & - \\
\hline \multirow[t]{2}{*}{ Jehna et al. ${ }^{25}:$ Austria } & FER: Ackerer face tasks & MS & $20(13 / 7)$ & 36.4 (9.3) & $13.65(1.90)$ & 3.46 & RR 7, SP 1, CIS 12 & $1.75(0.92)$ \\
\hline & & $\mathrm{HC}$ & $23(18 / 5)$ & $28.2(6.9)$ & $14.3(1.82)$ & - & - & - \\
\hline \multirow[t]{2}{*}{ Jehna et al. ${ }^{45}$ : Austria } & FER: BERT & MS & $15(10 / 5)$ & $29.47(9.61)$ & $13.80(2.91)$ & $7.27(6.46)$ & RR 15 & $1.7(1.1)$ \\
\hline & & $\mathrm{HC}$ & $15(10 / 5)$ & 30.27 (10.61) & 15.40 (3.02) & - & - & - \\
\hline \multirow[t]{2}{*}{ Kraemer et al. ${ }^{34}$ : Germany } & ToM: MASC & MS & $25(15 / 10)$ & $30.92(2.07)$ & $11.48(0.28)$ & $1.24(0.25)$ & RR 25 & 0.96 \\
\hline & & $\mathrm{HC}$ & $25(11 / 14)$ & $33.44(2.24)$ & $11.92(0.33)$ & - & - & - \\
\hline \multirow[t]{2}{*}{ Lenne et al. ${ }^{31}$ : France } & FER: Ekman Faces & MS & $55(44 / 11)$ & $39.84(8.74)$ & $13.49(2.81)$ & $7.52(5.93)$ & RR 55 & 2 \\
\hline & & $\mathrm{HC}$ & $21(13 / 8)$ & $36.38(10.14)$ & $14.14(2.54)$ & - & - & - \\
\hline \multirow[t]{2}{*}{ Mike et al. ${ }^{44}$ : Hungary } & ToM: RMitE, Faux Pas task, Adult Faces & MS & $49(31 / 18)$ & $39.82(9.31)$ & NR & 9.49 (6.19) & RR 44, SP 5 & $2.43(1.71)$ \\
\hline & & $\mathrm{HC}$ & $24(13 / 11)$ & $36.71(7.27)$ & NR & - & - & - \\
\hline \multirow[t]{3}{*}{ Ouellet et al..24: Canada } & ToM: Faux Pas task, Strange stories, C\&I & MS- & $26(15 / 11)$ & $45.2(7.3)$ & $13.7(2.6)$ & $10.2(8.1)$ & RR 11, PP 3, SP 11, NR 1 & $3.8(2.7)$ \\
\hline & & MS+ & $15(12 / 3)$ & $43.6(8.3)$ & $13.6(2.0)$ & $6.2(4.6)$ & RR 11, PP 2, SP 2 & $2.8(2.2)$ \\
\hline & & $\mathrm{HC}$ & $20(10 / 10)$ & 48.5 (8.2) & $14.6(1.9)$ & - & - & - \\
\hline \multirow[t]{2}{*}{ Parada-Fernández et al. ${ }^{54}:$ Spain } & FER: FEEL & MS & $45(29 / 16)$ & $49.44(9.44)$ & NR & $\mathrm{NR}$ & RR 24, PP 10, SP 6, RP 5 & NR \\
\hline & ToM: RMitE & $\mathrm{HC}$ & $40(20 / 20)$ & $50.78(10.08)$ & NR & - & - & - \\
\hline Passamonti et al. ${ }^{46}$ : Italy & FER: Ekman Faces & MS & $12(7 / 5)$ & $29.3(8.1)$ & $11.6(2.8)$ & $4.3(2.8)$ & RR 12 & 1.5 \\
\hline
\end{tabular}






years (range 1.2-18.4 years). Seventy-seven percent of patients had a relapsing-remitting course of illness. Between studies, the average EDSS scores reflecting the degree of physical disability ranged from 0.5 (no disability) to 6.5 (constant bilateral support [e.g., cane or crutch] required to walk 20 meters without resting) (median EDSS score 2.3). Most studies comprised patients with mild to moderate disability (12 samples reported an average EDSS score below 3). Studies typically excluded patients with visual or motor impairments that could confound performance on the social cognitive tasks, patients who had a relapse in the last 30-60 days, or those who had recently used steroid medications for this reason. General medication use was inconsistently reported; however, a large proportion of patients were receiving disease-modifying medication (typically interferon $\beta$ or glatiramer acetate).

Magnitude of deficits. Theory of mind. Effect sizes, sample size, and heterogeneity statistics for the overall and task-specific ToM scores are reported in table 2 . Overall ToM task performance was significantly worse in the MS group relative to controls (figure 2). None of the variables examined in the metaregression analyses predicted ToM task performance (all $p>0.13$ ) (table e- 1 and figure e-1 at Neurology. org). There was some evidence of statistical heterogeneity in the overall ToM effect size. The Egger regression test showed no evidence of publication bias for overall ToM $(b=1.324, \mathrm{SE}=2.07$, $p=0.27)$. The fail-safe $N$ was 291 , suggesting that there would need to be an additional 291 null studies in order for the combined 2-tailed $p$ value to exceed 0.05 . A sensitivity analysis excluding the only study to examine pediatric-onset $\mathrm{MS}^{27}$ did not alter the original effect size.

Individual ToM tasks. We also examined the differences between patients with MS and controls on the 3 most common types of ToM assessments (table 2). Patients with MS performed significantly worse than controls on the Reading the Mind in the Eyes test and on ToM video-based tasks. There was no statistically significant difference between patients with MS and the control group on Faux Pas recognition tasks.

Facial emotion recognition. Effect sizes, sample size, and heterogeneity statistics for the overall and emotion-specific facial emotion recognition scores are reported in table 2. Overall facial emotion recognition accuracy was significantly worse in the MS group relative to controls (figure 3). The metaregression analyses indicated that older age $(B=-0.031, \mathrm{SE}=0.01, Z=-2.56, p=0.01)$ was associated with greater deficits in overall facial emotion recognition among the MS group. None of the other variables were significant predictors of task 


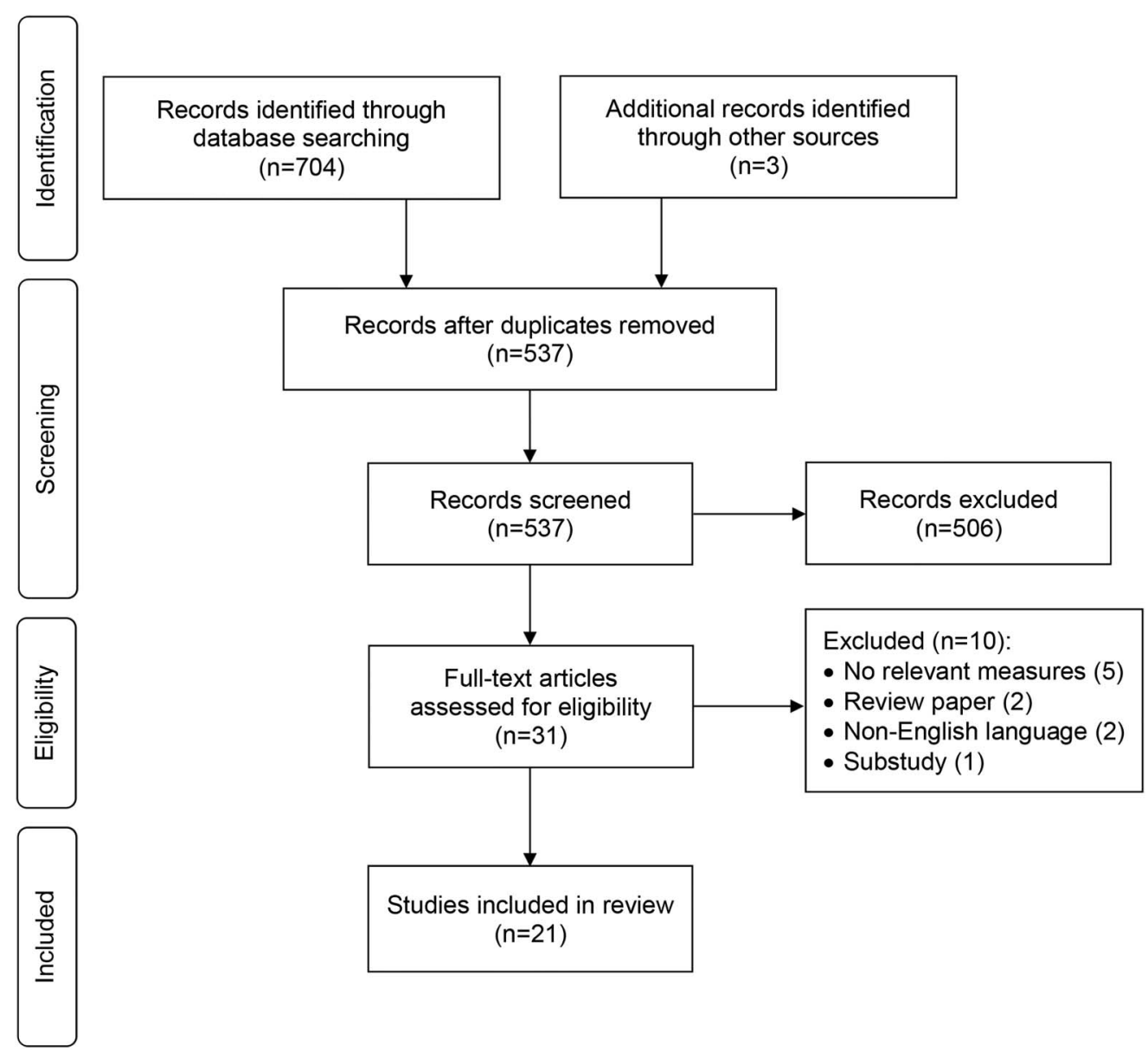

performance, though there were trend associations with EDSS score $(p=0.066)$ and disease duration $(p=0.086)$ (table e- 1 and figure e- 2 ). There was some evidence of low to moderate statistical heterogeneity in the overall facial emotion recognition effect size. The Egger regression test showed no evidence of publication bias for overall facial emotion recognition $(b=0.778, \mathrm{SE}=1.73, p=0.33)$ (figure e-3). The fail-safe $N$ was 257 . A sensitivity analysis excluding the only study to include patients with a clinically isolated syndrome ${ }^{25}$ had a negligible impact on the results.

Table 2 Mean weighted effect sizes, sample sizes, and heterogeneity statistics

$\begin{array}{llllllllll}\text { Test } & \text { No. of studies } & \text { No. (MS) } & \text { No. (controls) } & \text { Hedges } \mathrm{g} & 95 \% \mathrm{Cl} & Z & p & \mathrm{I}^{2}(95 \% \mathrm{Cl}) & \mathrm{H}^{2}(95 \% \mathrm{Cl}) \\ \text { ToM (overall) } & 13 & 429 & 345 & -0.71 & -0.88 \text { to }-0.55 & -8.38 & <0.001 & 23 \%(0-59.8) & 1.30(1.00-2.49) \\ \text { Faux Pas } & 7 & 240 & 157 & -0.26 & -0.58 \text { to } 0.07 & -1.56 & 0.119 & 61 \%(10.8-83.0) & 2.56(1.12-5.87) \\ \text { RMitE } & 5 & 189 & 161 & -0.92 & -1.15 \text { to }-0.70 & -8.01 & <0.001 & 4 \%(0-80) & 1.04(1.00-5.01) \\ \text { Video task } & 6 & 158 & 138 & -0.65 & -0.92 \text { to }-0.37 & -4.66 & <0.001 & 29 \%(0-70.9) & 1.41(1.00-3.44) \\ \text { FER (overall) } & 13 & 473 & 423 & -0.64 & -0.81 \text { to }-0.47 & -7.23 & <0.001 & 36 \%(0-66.9) & 1.56(1.00-3.02) \\ \text { Anger } & 8 & 344 & 301 & -0.58 & -0.81 \text { to }-0.36 & -5.03 & <0.001 & 49 \%(0-77.3) & 1.96(1.00-4.40) \\ \text { Disgust } & 7 & 289 & 280 & -0.24 & -0.51 \text { to } 0.03 & -1.72 & 0.086 & 62 \%(13.4-83.3) & 2.63(1.15-6.00) \\ \text { Fear } & 8 & 344 & 301 & -0.56 & -0.81 \text { to }-0.32 & -4.49 & <0.001 & 56 \%(3-80) & 2.27(1.03-5.01) \\ \text { Happiness } & 8 & 344 & 301 & -0.14 & -0.35 \text { to } 0.07 & -1.31 & 0.190 & 41 \%(0-73.9) & 1.69(1.00-3.84) \\ \text { Sadness } & 8 & 344 & 301 & -0.35 & -0.54 \text { to }-0.17 & -3.72 & <0.001 & 26 \%(0-66.5) & 1.35(1.00-3.00) \\ \text { Surprise } & 7 & 289 & 280 & -0.25 & -0.50 \text { to } 0.01 & -1.91 & 0.056 & 55 \%(0-80.7) & 2.22(1.00-5.18)\end{array}$

Abbreviations: $\mathrm{Cl}=$ confidence interval; $\mathrm{FER}=$ facial emotion recognition; $\mathrm{MS}=$ multiple sclerosis; RMitE $=$ Reading the Mind in the Eyes test; ToM = theory of mind. 
Figure 2 Forest plot of theory of mind in patients with MS vs healthy controls

Study

\begin{tabular}{|c|c|c|c|c|c|c|c|}
\hline & Hedges $\mathbf{g}$ & $\begin{array}{l}\text { Standar } \\
\text { error }\end{array}$ & $\begin{array}{l}\text { d Lower } \\
\text { limit }\end{array}$ & $\begin{array}{l}\text { Upper } \\
\text { limit }\end{array}$ & $z$ value & $\begin{array}{l}\text { Relative } \\
\text { weight }\end{array}$ & $p$ value \\
\hline Ref \#53 & -0.577 & 0.240 & -1.047 & -0.107 & -2.405 & 9.18 & 0.016 \\
\hline Ref \#27 & -0.697 & 0.263 & -1.213 & -0.181 & -2.647 & 7.99 & 0.008 \\
\hline Ref \#30 & -1.051 & 0.380 & -1.796 & -0.306 & -2.764 & 4.37 & 0.006 \\
\hline Ref \#28 & -0.831 & 0.273 & -1.366 & -0.296 & -3.044 & 7.56 & 0.002 \\
\hline Ref \#33 & -0.616 & 0.224 & -1.056 & -0.176 & -2.744 & 10.10 & 0.006 \\
\hline Ref \#34 & -0.363 & 0.281 & -0.914 & 0.187 & -1.294 & 7.23 & 0.196 \\
\hline Ref \#44 & -0.620 & 0.255 & -1.120 & -0.120 & -2.432 & 8.39 & 0.015 \\
\hline Ref \#24 (MS- group) & -0.602 & 0.299 & -1.189 & -0.015 & -2.009 & 6.53 & 0.045 \\
\hline Ref \#24 (MS+ group) & 0.052 & 0.334 & -0.602 & 0.706 & 0.156 & 5.46 & 0.876 \\
\hline Ref \#54 & -1.318 & 0.238 & -1.784 & -0.852 & -5.541 & 9.29 & 0.000 \\
\hline Ref \#11 & -0.835 & 0.256 & -1.336 & -0.334 & -3.264 & 8.35 & 0.001 \\
\hline Ref \#29 & -0.793 & 0.217 & -1.219 & -0.367 & -3.651 & 10.56 & 0.000 \\
\hline \multirow[t]{2}{*}{ Ref \#35 } & -0.875 & 0.352 & -1.565 & -0.185 & -2.487 & 5.00 & 0.013 \\
\hline & -0.714 & 0.085 & -0.881 & -0.547 & -8.377 & & 0.000 \\
\hline
\end{tabular}

Hedges $\mathrm{g}$ and $95 \% \mathrm{Cl}$
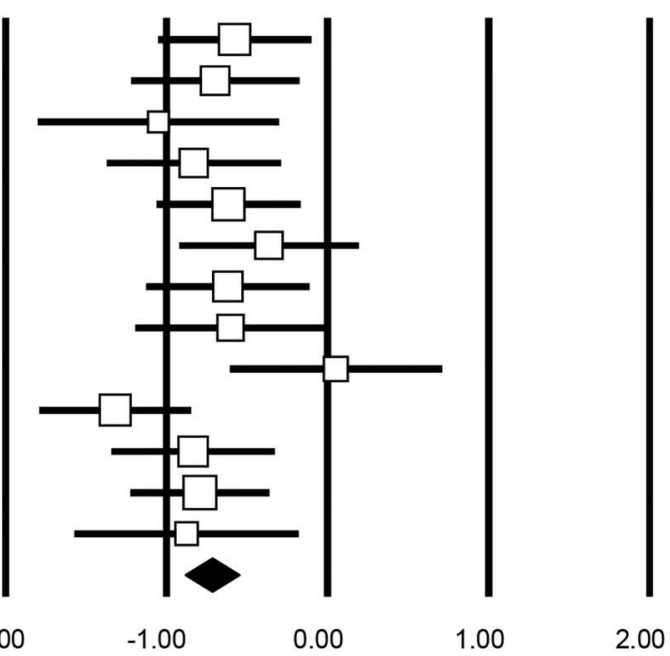

Worse than controls

$\mathrm{Cl}=$ confidence interval; $\mathrm{MS}=$ multiple sclerosis.

Identification of specific emotional expressions. We performed additional analyses to examine the patients' ability to identify each of the 6 specific basic emotional facial expressions (table 2). Effect sizes indicated deficits among the MS group in recognition of all types of emotional facial expressions; however, statistically significant deficits were identified only for anger, sadness, and fear. There were no statistically significant differences for labeling of happiness, disgust, or surprise.

Relationship with neurocognitive impairment, depression, and fatigue. Evidence to date suggests social cognitive dysfunction may occur both independently and secondary to neurocognitive deficits. There is evidence that social cognitive deficits are greater among

Figure 3 Forest plot of facial emotion recognition in patients with MS vs healthy controls

Study

\begin{tabular}{|c|c|c|c|c|c|c|c|}
\hline & Hedges $\mathbf{g}$ & $\begin{array}{c}\text { Standard } \\
\text { error }\end{array}$ & $\begin{array}{c}\text { Lower } \\
\text { limit }\end{array}$ & $\begin{array}{l}\text { Upper } \\
\text { limit }\end{array}$ & $z$ value & $\begin{array}{c}\text { Relative } \\
\text { weight }\end{array}$ & $p$ va \\
\hline Ref \#36 & -1.217 & 0.339 & -1.881 & -0.553 & -3.591 & 5.23 & 0.000 \\
\hline Ref \#37 & -0.807 & 0.194 & -1.187 & -0.427 & -4.160 & 10.74 & 0.000 \\
\hline Ref \#38 & -0.588 & 0.260 & -1.098 & -0.077 & -2.257 & 7.60 & 0.024 \\
\hline Ref \#28 & -0.354 & 0.264 & -0.871 & 0.163 & -1.343 & 7.48 & $0.17 \mathrm{~s}$ \\
\hline Ref \#33 & -0.938 & 0.230 & -1.388 & -0.487 & -4.080 & 8.89 & 0.00 \\
\hline Ref \#25 & -0.451 & 0.304 & -1.047 & 0.145 & -1.483 & 6.14 & 0.13 \\
\hline Ref \#45 & -0.048 & 0.355 & -0.745 & 0.648 & -0.136 & 4.86 & 0.892 \\
\hline Ref \#31 & -0.928 & 0.265 & -1.447 & -0.409 & -3.503 & 7.44 & 0.00 \\
\hline Ref \#46 & -0.112 & 0.395 & -0.885 & 0.661 & -0.284 & 4.11 & 0.777 \\
\hline Ref \#11 & -0.810 & 0.255 & -1.310 & -0.310 & -3.174 & 7.80 & 0.002 \\
\hline Ref \#32 & -0.224 & 0.188 & -0.593 & 0.145 & -1.191 & 11.07 & 0.233 \\
\hline Ref \#39 & -0.781 & 0.218 & -1.208 & -0.354 & -3.585 & 9.47 & 0.000 \\
\hline \multirow[t]{2}{*}{ Ref \#54 } & -0.764 & 0.224 & -1.202 & -0.326 & -3.416 & 9.18 & 0.00 \\
\hline & -0.641 & 0.089 & -0.814 & -0.467 & -7.227 & & 0.00 \\
\hline
\end{tabular}

Hedges $\mathrm{g}$ and $95 \% \mathrm{Cl}$



Worse than controls

Better than controls

$\mathrm{Cl}=$ confidence interval; $\mathrm{MS}=$ multiple sclerosis. 
patients with MS with more severe neurocognitive impairment. ${ }^{24}$ Significant positive correlations have also been reported between both ToM and facial emotion recognition task performance and neurocognitive measures of processing speed, ${ }^{28,29}$ working memory, ${ }^{30,31}$ and executive function. ${ }^{28,32}$ However, the strength and statistical significance of these associations was inconsistent, ${ }^{25,28-35}$ which may be at least partially attributable to differences in task demands. Studies have also reported that social cognition remained significantly impaired among patients with MS even after controlling for neurocognitive performance or after excluding those patients with cognitive impairment. ${ }^{1,29}$ Despite early work suggesting facial emotion recognition deficits were due to general problems discriminating between faces, ${ }^{36}$ more recent work indicated that these deficits also occurred in those with intact facial recognition, suggesting this deficit is due to a specific emotional rather than perceptual impairment. ${ }^{11,37-39}$

Eleven of the studies in this review explicitly excluded patients with major depressive disorder. Though depressive symptoms were generally higher in the MS groups, no studies examining ToM reported associations between depressive symptoms and task performance and only 3 assessing facial emotion recognition did so. ${ }^{31,32,37}$ Similarly, fatigue was unrelated to performance on ToM tasks ${ }^{33,35}$ and evidence linking it to facial emotion recognition was inconsistent. ${ }^{33,37,38}$

DISCUSSION Our results show significant deficits in the ability of patients with MS to identify and discriminate between the mental and emotional states of others relative to healthy controls. It is important to consider that these deficits were observed among a sample with a relatively young mean age (39.9 years), short disease duration (mean 8 years), mild to moderate degree of physical disability (median EDSS score 2.3), and predominantly relapsingremitting course of illness (77\%). Specific deficits were identified in the labeling of sad, fearful, and angry facial expressions. Among ToM tasks, patients with MS showed impairment in their ability to infer the mental states of others during visual tasks based on both images and videos. Deficits appeared to a degree independent of global neurocognitive impairment, though findings were inconsistent.

Previous reviews among patients with relapsingremitting MS have reported global deficits in neurocognitive functioning ( $\mathrm{g}=0.58$ ) relative to healthy controls, as well as domain-specific deficits in areas including memory $(\mathrm{g}=0.60)$, attention and executive ability $(\mathrm{g}=0.55)$, and verbal functions and language $(g=0.44) .^{2}$ The findings of this review suggest that social cognitive deficits are similar or greater in magnitude to those observed in other aspects of cognition in this patient group. Deficits in ToM and facial emotion recognition among those with MS were not as severe as those identified in patients with schizophrenia $(\mathrm{g}=0.88-0.96)^{10}$ or in other neurodegenerative disorders such as Parkinson disease (Cohen $d=0.83$ ). ${ }^{40}$ However, they appear to be worse than those reported in attention-deficit/ hyperactivity disorder (Cohen $d=0.44-0.45)^{7}$ and major depressive disorder $(\mathrm{g}=0.16-0.51){ }^{8,41}$

To date, social cognitive research in MS has consisted of small, cross-sectional studies, conducted primarily in patients with a relapsing-remitting disease course and modest level of physical disability. This earlier disease course is characterized by bouts of inflammation and periods of recovery and remyelination. ${ }^{42}$ When the disease advances to a progressive course, episodes of inflammation and demyelination become more infrequent, with a shift towards neurodegeneration and sustained damage. This has implications for the generalizability of these findings and highlights the need for research investigating the longitudinal course of social cognitive dysfunction. More research is needed in patients with a progressive course of illness and more severe physical disability to establish the extent to which the results of this review are generalizable to this patient group. This should ideally include repeated assessments over long-term follow-up and neuroimaging to permit more detailed examination of the relationship between disease characteristics and progression, tissue damage, and social cognitive dysfunction. The limited structural and functional imaging evidence among patients with MS to date suggests that social cognitive deficits may be due to abnormalities in the neural circuitry that underlie these processes. ${ }^{43-46}$ However, further analyses, particularly for ToM, are warranted to improve our understanding of social cognitive decline. Similarly, the relationship between social cognitive and neurocognitive deficits in MS remains unclear and would benefit from longitudinal evaluation.

Social cognitive research in MS has focused almost entirely on ToM and facial emotion recognition. Although studies have also investigated vocal ${ }^{47,48}$ and bodily affect recognition ${ }^{38}$ in this patient group, there were too few to allow inclusion in the current review. In addition, only English-language articles were eligible for inclusion, which led to the exclusion of 2 non-English-language articles found in the electronic search. However, the large fail-safe $N$ and lack of evidence suggestive of publication bias for both ToM and facial emotion recognition suggest that our findings were robust.

There was evidence of low to moderate statistical heterogeneity in the effect size estimates. This is likely 
to have been driven by differences in the clinical and demographic characteristics of the study samples and the social cognitive tasks that were used. Facial emotion recognition tasks required individuals to label images of faces depicting up to 6 basic emotions. In contrast, ToM was assessed using a wide variety of tasks. Additional analyses investigating performance on the 3 most common types of ToM tasks indicated that patients with MS exhibited marked impairment in their ability to infer the mental states of others during visual tasks. However, nonsignificant deficits were found for performance on Faux Pas recognition tasks. High levels of heterogeneity in the effect size estimate for the Faux Pas recognition tasks may have been driven by alterations in these subtle tests due to translation, modification, or child versions being used. There was also some overlap between social cognitive domains. For example, the Reading the Mind in the Eyes test ${ }^{19}$ was classed as a ToM measure as it requires the identification of complex mental states; however, it also includes emotion recognition items. Similarly, ToM video tasks typically require competence in emotion recognition and social knowledge. This tentatively suggests that the largest deficits in ToM are observed in those tasks with an affective component.

In addition to the meta-analysis, we conducted exploratory meta-regression analyses. These should be interpreted with caution. Although these provide a useful tool to visualize the relationship between social cognitive performance and each of the clinical and demographic variables, they are underpowered to detect anything but very large study-level effects since they only include aggregate data from a relatively small number of studies.

MS is a disease characterized by considerable patient heterogeneity in clinical presentation, lesion profiles, and cognitive dysfunction., ${ }^{4,49,50}$ Despite this variation, this review identified consistent deficits in the domains of ToM and facial emotion recognition. Individual studies suggested this was the case even among patients with early MS. ${ }^{27}$ Social cognitive deficits have been identified as potentially important predictors of quality of life among patients with $\mathrm{MS},{ }^{11}$ and warrant further attention. Further research is required to clarify the longitudinal course of social cognitive dysfunction, its association with MS disease characteristics and neurocognitive impairment, and the MSspecific neurologic damage underlying these deficits.

The results of this review emphasize the need to increase awareness among treating physicians of social cognitive dysfunction. They also support recent calls for monitoring of social cognition to be incorporated into routine neurologic assessments. ${ }^{51}$ Current cognitive test batteries developed for clinical use in patients with MS include only neurocognitive tasks. Evidence from this review suggests that social cognitive deficits may be comparable in magnitude to or even exceed other neurocognitive impairments and should also be considered for inclusion. This raises the possibility of identifying early and subtle impairments and potentially intervening before deficits become more pronounced. This may be particularly important among patients with pediatric-onset MS. Social cognitive skills are likely to still be developing in these young people and early deficits may be more damaging for the development of social skills in the longer term. Social cognitive training has been shown to be effective in other disorders $^{52}$ and it is hoped that the results of this review can potentially help inform the development of similar interventions for those with MS.

\section{AUTHOR CONTRIBUTIONS}

Jack Cotter: review concept and design, literature search, data extraction, statistical analyses, interpretation of data, drafting and revision of manuscript. Joseph Firth: data extraction, interpretation of data, critical revision of manuscript for intellectual content. Christian Enzinger: interpretation of data, critical revision of manuscript for intellectual content. Evangelos Kontopantelis: technical guidance with statistical analyses, interpretation of data, critical revision of manuscript for intellectual content. Alison Yung: interpretation of data, critical revision of manuscript for intellectual content. Rebecca Elliott: interpretation of data, critical revision of manuscript for intellectual content. Richard Drake: interpretation of data, critical revision of manuscript for intellectual content.

\section{ACKNOWLEDGMENT}

The authors thank the following individuals for providing additional data from their original articles for this review: Professor Zsolt Illes (University of Southern Denmark), Professor Louise Phillips (University of Aberdeen, UK), Cinzia Cecchetto (Scuola Internazionale Superiore di Studi Avanzati, Italy), Dr. Matthias Grothe and Professor Alexander Dressel (University of Greifswald, Germany), Professor Julie Henry (University of Queensland, Australia), Dr. Denise Potthoff and Professor Rüdiger Seitz (University of Düsseldorf, Germany), and Dr. Margit Jehna (Medical University of Graz, Austria).

\section{STUDY FUNDING}

Dr. Kontopantelis is supported by an MRC Health eResearch Centre grant MR/K006665/1.

\section{DISCLOSURE}

J. Cotter and J. Firth report no disclosures relevant to the manuscript. C. Enzinger has received funding for travel and speaker honoraria from Biogen Idec, Bayer Schering Pharma, Merck Serono, Novartis Genzyme, and Teva Pharmaceutical Industries Ltd./Sanofi-Aventis; has received research support from Merck Serono, Biogen Idec., and Teva Pharmaceutical Industries Ltd./Sanofi-Aventis; and served on scientific advisory boards for Bayer Schering Pharma, Biogen Idec, Genzyme, Merck Serono, Novartis, and Teva Pharmaceutical Industries Ltd./Sanofi-Aventis. E. Kontopantelis, A. Yung, R. Elliott, and R. Drake report no disclosures relevant to the manuscript. Go to Neurology.org for full disclosures.

Received April 29, 2016. Accepted in final form July 5, 2016.

\section{REFERENCES}

1. Langdon DW. Cognition in multiple sclerosis. Curr Opin Neurol 2011;24:244-249.

2. Prakash RS, Snook EM, Lewis JM, Motl RW, Kramer AF. Cognitive impairments in relapsing-remitting multiple sclerosis: a meta-analysis. Mult Scler 2008;14:1250-1261.

3. Ruet A, Deloire M, Charré-Morin J, Hamel D, Brochet B. Cognitive impairment differs between primary progressive and relapsing-remitting MS. Neurology 2013;80:1501-1508. 
4. Chiaravalloti ND, DeLuca J. Cognitive impairment in multiple sclerosis. Lancet Neurol 2008;7:1139-1151.

5. Green MF, Penn DL, Bentall R, et al. Social cognition in schizophrenia: an NIMH workshop on definitions, assessment, and research opportunities. Schizophr Bull 2008;34: 1211-1220.

6. Baron-Cohen S, Leslie AM, Frith U. Does the autistic child have a "theory of mind"? Cognition 1985;21:37-46.

7. Bora E, Pantelis C. Meta-analysis of social cognition in attention-deficit/hyperactivity disorder (ADHD): comparison with healthy controls and autistic spectrum disorder. Psychol Med 2016;46:699-716.

8. Dalili MN, Penton-Voak IS, Harmer CJ, Munafo MR. Meta-analysis of emotion recognition deficits in major depressive disorder. Psychol Med 2015;45:1135-1144.

9. Poletti M, Enrici I, Adenzato M. Cognitive and affective theory of mind in neurodegenerative diseases: neuropsychological, neuroanatomical and neurochemical levels. Neurosci Biobehav Rev 2012;36:2147-2164.

10. Savla GN, Vella L, Armstrong CC, Penn DL, Twamley EW. Deficits in domains of social cognition in schizophrenia: a meta-analysis of the empirical evidence. Schizophr Bull 2013;39:979-992.

11. Phillips LH, Henry JD, Scott C, Summers F, Whyte M, Cook M. Specific impairments of emotion perception in multiple sclerosis. Neuropsychology 2011;25:131-136.

12. Green MF, Horan WP. Social cognition in schizophrenia. Curr Dir Psychol Sci 2010;19:243-248.

13. Fett AK, Viechtbauer W, Dominguez MD, Penn DL, van Os J, Krabbendam L. The relationship between neurocognition and social cognition with functional outcomes in schizophrenia: a meta-analysis. Neurosci Biobehav Rev 2011;35:573-588.

14. Moher D, Liberati A, Tetzlaff J, Altman DG; PRISMA Group. Preferred Reporting Items for Systematic Reviews and MetaAnalyses: the PRISMA statement. BMJ 2009;339:b2535.

15. McDonald WI, Compston A, Edan G, et al. Recommended diagnostic criteria for multiple sclerosis: guidelines from the International Panel on the Diagnosis of Multiple Sclerosis. Ann Neurol 2001;50:121-127.

16. Poser CM, Paty DW, Scheinberg L, et al. New diagnostic criteria for multiple sclerosis: guidelines for research protocols. Ann Neurol 1983;13:227-231.

17. Ekman P, Friesen WV. Pictures of Facial Affect. Palo Alto, CA: Consulting Psychologists Press; 1976.

18. Borenstein M, Hedges L, Higgins J, Rothstein H. Comprehensive Meta-analysis: A Computer Program for Metaanalysis. Englewood, NJ: Biostat Inc.; 2007.

19. Baron-Cohen $S$, Wheelwright $S$, Hill J, Raste $Y$, Plumb I. The "Reading the Mind in the Eyes" Test revised version: a study with normal adults, and adults with Asperger syndrome or high-functioning autism. J Child Psychol Psychiatry 2001;42:241-251

20. Brockwell SE, Gordon IR. A comparison of statistical methods for meta-analysis. Stat Med 2001;20:825-840.

21. Kontopantelis E, Reeves D. Performance of statistical methods for meta-analysis when true study effects are non-normally distributed: a simulation study. Stat Methods Med Res 2012;21:409-426.

22. Higgins JP, Thompson SG. Quantifying heterogeneity in a meta-analysis. Stat Med 2002;21:1539-1558.

23. Kurtzke JF. Rating neurologic impairment in multiple sclerosis: an expanded disability status scale (EDSS). Neurology 1983;33:1444-1452.
24. Ouellet J, Scherzer PB, Rouleau I, et al. Assessment of social cognition in patients with multiple sclerosis. J Int Neuropsychol Soc 2010;16:287-296.

25. Jehna M, Neuper C, Petrovic K, et al. An exploratory study on emotion recognition in patients with a clinically isolated syndrome and multiple sclerosis. Clin Neurol Neurosurg 2010;112:482-484.

26. Miller DH, Chard DT, Ciccarelli O. Clinically isolated syndromes. Lancet Neurol 2012;11:157-169.

27. Charvet LE, Cleary RE, Vazquez K, Belman AL, Krupp LB; US Network for Pediatric MS. Social cognition in pediatric-onset multiple sclerosis (MS). Mult Scler 2014;20:1478-1484.

28. Henry JD, Phillips LH, Beatty WW, et al. Evidence for deficits in facial affect recognition and theory of mind in multiple sclerosis. J Int Neuropsychol Soc 2009;15:277-285.

29. Pöttgen J, Dziobek I, Reh S, Heesen C, Gold SM. Impaired social cognition in multiple sclerosis. J Neurol Neurosurg Psychiatry 2013;84:523-528.

30. Genova HM, Cagna CJ, Chiaravalloti ND, DeLuca J, Lengenfelder J. Dynamic assessment of social cognition in individuals with multiple sclerosis: a pilot study. J Int Neuropsychol Soc 2016;22:83-88.

31. Lenne B, Barthelemy R, Nandrino JL, et al. Impaired recognition of facial emotional expressions in multiple sclerosis. Neuropsychol Trends 2014;15:67-83.

32. Pinto C, Gomes F, Moreira I, et al. Emotion recognition in multiple sclerosis. JETVCE 2012;2:76-81.

33. Henry A, Tourbah A, Chaunu MP, Rumbach L, Montreuil M, Bakchine S. Social cognition impairments in relapsing-remitting multiple sclerosis. J Int Neuropsychol Soc 2011;17:1122-1131.

34. Kraemer M, Herold M, Uekermann J, et al. Theory of mind and empathy in patients at an early stage of relapsing remitting multiple sclerosis. Clin Neurol Neurosurg 2013;115:1016-1022.

35. Roca M, Manes F, Gleichgerrcht E, et al. Cognitive but not affective theory of mind deficits in mild relapsing-remitting multiple sclerosis. Cogn Behav Neurol 2014;27:25-30.

36. Beatty WW, Goodkin DE, Weir WS, Staton RD, Monson N, Beatty PA. Affective judgments by patients with Parkinson's disease or chronic progressive multiple sclerosis. Bull Psychon Soc 1989;27:361-364.

37. Berneiser J, Wendt J, Grothe M, Kessler C, Hamm AO, Dressel A. Impaired recognition of emotional facial expressions in patients with multiple sclerosis. Mult Scler Relat Disord 2014;3:482-488.

38. Cecchetto C, Aiello M, D'Amico D, et al. Facial and bodily emotion recognition in multiple sclerosis: the role of alexithymia and other characteristics of the disease. J Int Neuropsychol Soc 2014;20:1004-1014.

39. Prochnow D, Donell J, Schäfer R, et al. Alexithymia and impaired facial affect recognition in multiple sclerosis. J Neurol 2011;258:1683-1688.

40. Bora E, Walterfang M, Velakoulis D. Theory of mind in Parkinson's disease: a meta-analysis. Behav Brain Res 2015;292:515-520.

41. Bora E, Berk M. Theory of mind in major depressive disorder: a meta-analysis. J Affect Disord 2016;191:49-55.

42. Compston A, Coles A. Multiple sclerosis. Lancet 2008; 372:1502-1517.

43. Krause M, Wendt J, Dressel A, et al. Prefrontal function associated with impaired emotion recognition in patients with multiple sclerosis. Behav Brain Res 2009;205:280-285. 
44. Mike A, Strammer E, Aradi M, et al. Disconnection mechanism and regional cortical atrophy contribute to impaired processing of facial expressions and theory of mind in multiple sclerosis: a structural MRI study. PLoS One 2013;8:e82422.

45. Jehna M, Langkammer C, Wallner-Blazek M, et al. Cognitively preserved MS patients demonstrate functional differences in processing neutral and emotional faces. Brain Imaging Behav 2011;5:241-251.

46. Passamonti L, Cerasa A, Liguori M, et al. Neurobiological mechanisms underlying emotional processing in relapsingremitting multiple sclerosis. Brain 2009;132:3380-3391.

47. Beatty WW, Orbelo DM, Sorocco KH, Ross ED. Comprehension of affective prosody in multiple sclerosis. Mult Scler 2003;9:148-153.

48. Kraemer M, Herold M, Uekermann J, et al. Perception of affective prosody in patients at an early stage of relapsingremitting multiple sclerosis. J Neuropsychol 2013;7:91-106.

49. Lucchinetti C, Brück W, Parisi J, Scheithauer B, Rodriguez M, Lassmann H. Heterogeneity of multiple sclerosis lesions: implications for the pathogenesis of demyelination. Ann Neurol 2000;47:707-717.

50. Weiner HL. The challenge of multiple sclerosis: how do we cure a chronic heterogeneous disease? Ann Neurol 2009;65:239-248.

51. Henry JD, von Hippel W, Molenberghs P, Lee T, Sachdev PS. Clinical assessment of social cognitive function in neurological disorders. Nat Rev Neurol 2016;12: 28-39.

52. Kurtz MM, Gagen E, Rocha NB, Machado S, Penn DL. Comprehensive treatments for social cognitive deficits in schizophrenia: a critical review and effect-size analysis of controlled studies. Clin Psychol Rev 2016;43:80-89.

53. Banati M, Sandor J, Mike A, et al. Social cognition and theory of mind in patients with relapsing-remitting multiple sclerosis. Eur J Neurol 2010;17:426-433.

54. Parada-Fernández P, Oliva-Macías M, Amayra I, et al. Accuracy and reaction time in recognition of facial emotions in people with multiple sclerosis. Rev Neurol 2015; 61:433-440. 


\section{Neurology}

\section{Social cognition in multiple sclerosis: A systematic review and meta-analysis Jack Cotter, Joseph Firth, Christian Enzinger, et al.}

Neurology 2016;87;1727-1736 Published Online before print September 21, 2016

DOI 10.1212/WNL.0000000000003236

This information is current as of September 21, 2016

\begin{tabular}{|c|c|}
\hline $\begin{array}{l}\text { Updated Information \& } \\
\text { Services }\end{array}$ & $\begin{array}{l}\text { including high resolution figures, can be found at: } \\
\text { http://n.neurology.org/content/87/16/1727.full }\end{array}$ \\
\hline Supplementary Material & $\begin{array}{l}\text { Supplementary material can be found at: } \\
\text { http://n.neurology.org/content/suppl/2016/09/21/WNL.0000000000003 } \\
\text { 236.DC1 }\end{array}$ \\
\hline References & $\begin{array}{l}\text { This article cites } 52 \text { articles, } 4 \text { of which you can access for free at: } \\
\text { http://n.neurology.org/content/87/16/1727.full\#ref-list-1 }\end{array}$ \\
\hline Citations & $\begin{array}{l}\text { This article has been cited by } 2 \text { HighWire-hosted articles: } \\
\text { http://n.neurology.org/content/87/16/1727.full\#\#otherarticles }\end{array}$ \\
\hline Subspecialty Collections & $\begin{array}{l}\text { This article, along with others on similar topics, appears in the } \\
\text { following collection(s): } \\
\text { Multiple sclerosis } \\
\text { http://n.neurology.org/cgi/collection/multiple_sclerosis }\end{array}$ \\
\hline Permissions \& Licensing & $\begin{array}{l}\text { Information about reproducing this article in parts (figures,tables) or in } \\
\text { its entirety can be found online at: } \\
\text { http://www.neurology.org/about/about_the_journal\#permissions }\end{array}$ \\
\hline Reprints & $\begin{array}{l}\text { Information about ordering reprints can be found online: } \\
\text { http://n.neurology.org/subscribers/advertise }\end{array}$ \\
\hline
\end{tabular}

Neurology ${ }^{\circledR}$ is the official journal of the American Academy of Neurology. Published continuously since 1951, it is now a weekly with 48 issues per year. Copyright @ 2016 American Academy of Neurology. All rights reserved. Print ISSN: 0028-3878. Online ISSN: 1526-632X.

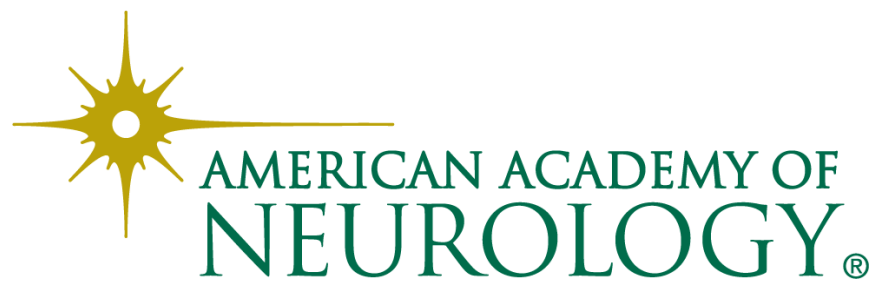

